\title{
Simulation of the downstream processing in the ethanol production from lignocellulosic biomass with ASPEN Plus ${ }^{\circledast}$ and IPSEpro
}

\author{
Tino Lassmann*, Philipp Kravanja and Anton Friedl
}

\begin{abstract}
Background: One of the most promising alternatives to gasoline as fuel in the transport industry is bioethanol, whether if it is conventional (based on raw materials containing sugar and starch) or produced from lignocellulosic biomass. Unfortunately, the energy intensive downstream process in lignocellulosic bioethanol production still limits the ability to compete with conventional bioethanol or petroleum. A process setup that provides possibilities for heat integration would consequently result in a more efficient overall process and increase its competitiveness.

Methods: In this work, two different distillation concepts, with an annual production of 100,000 tons of ethanol from straw, are simulated with the modeling tool ASPEN Plus ${ }^{\oplus}$. To round out the downstream process, simulations of an evaporation system and an anaerobic digester to produce biogas provide results for these two possibilities of subsequent stillage treatment. Furthermore, the simulations done with IPSEpro provide data for pinch analysis of the overall bioethanol process. By applying pinch analysis, the concepts are compared from an energy point of view, to find the optimal distillation concept in context with the background process for the respective subsequent stillage treatment.
\end{abstract}

Results: The results from pinch analysis show that the three-column distillation setup is in favor for both stillage treatment methods. For the concept including five-stage evaporation, the minimum energy consumption per kilogram of ethanol accounts for $17.2 \mathrm{MJ} / \mathrm{kg}_{\mathrm{EtOH}}$. When anaerobic digestion is used to treat the distillation stillage, only $10 \mathrm{MJ} / \mathrm{kg}_{\mathrm{EtOH}}$ has to be provided.

Conclusions: An important criteria to specify a process is the overall process efficiency. The overall process efficiency can be improved by reducing the downstream energy consumption, especially in the distillation section. With the best fitting configuration of distillation and stillage treatment concepts the efficiency is improved and by-products as heat, electricity, and pellets allocated.

Keywords: Bioethanol; Straw; Lignocellulose; Pinch analysis; Simulation; Biogas

\section{Background}

Bioethanol is identified as an undenatured ethanol with an alcohol content higher than 99 vol\%, generated from biogenic feedstock [1]. Based on the raw material used, first- and second-generation bioethanol have to be distinguished. The former utilizes raw materials containing starch and sugar, such as potatoes, wheat, corn, sugar beet, and sugar cane. With this well-established manufacturing method, most of the commercially available bioethanol is

\footnotetext{
* Correspondence: tino.lassmann@tuwien.ac.at

Institute of Chemical Engineering, Vienna University of Technology, Getreidemarkt 9/166, A-1060 Vienna, Austria
}

produced. In contrast to the level of development of first-generation bioethanol, the production of secondgeneration bioethanol is still in its infancy. Based on lignocellulosic feedstock such as wheat straw or spruce, its favorable properties compared to gasoline, the high $\mathrm{CO}_{2}$ reduction potential and the circumvention of the 'dinner plate to fuel tank' discussion are in lignocellulosic bioethanol's favor.

Even though the unit operations of the process are similar for the production of first- and second-generation bioethanol, the latter presents a special challenge for the biotechnological production of ethanol especially from a 
technological point of view. The sugars present in the cellulose and in the hemicellulose are less accessible than the sugars from starch or sugar cane juice. Furthermore, the content of sugars in the lignocellulosic feedstock is lower than in the conventional raw materials such as wheat or sugar cane, which results in a large proportion of the raw material energy remaining in the slurry after the fermentation and the distillation. One possible process variation for the production of bioethanol based on lignocellulosic raw material is shown in Figure 1. In this particular case, the downstream process steps for second-generation bioethanol, from distillation to the end product, are highlighted. With an ethanol concentration around $4 \mathrm{wt} \%$ after fermentation, the distillation in the second-generation ethanol production is more energy intensive than in the first-generation ethanol production (up to $17 \mathrm{wt} \%$ ) [2]. This comparatively low ethanol concentration originates from the upstream process steps pretreatment, hydrolysis and fermentation.

\section{Upstream process}

In the pretreatment section a surface area enlargement, by milling for example, increases the efficiency of the subsequent hydrolysis [3]. There, the $\mathrm{C}_{5^{-}}$and $\mathrm{C}_{6}$-sugars are broken down to monosaccharides which makes them accessible for fermentation to ethanol. For hydrolysis, either acids or enzymes can be used. Depending on the procedure chosen, the yield results in a range from 50\% to $95 \%$ [4]. In this work, the enzymatic hydrolysis is selected with steam explosion as an additional pretreatment step to make the composite-like lignocellulosic structure accessible for enzymatic attack. Furthermore, the process steps hydrolysis and fermentation are done simultaneously in the same reactor, which is denoted as

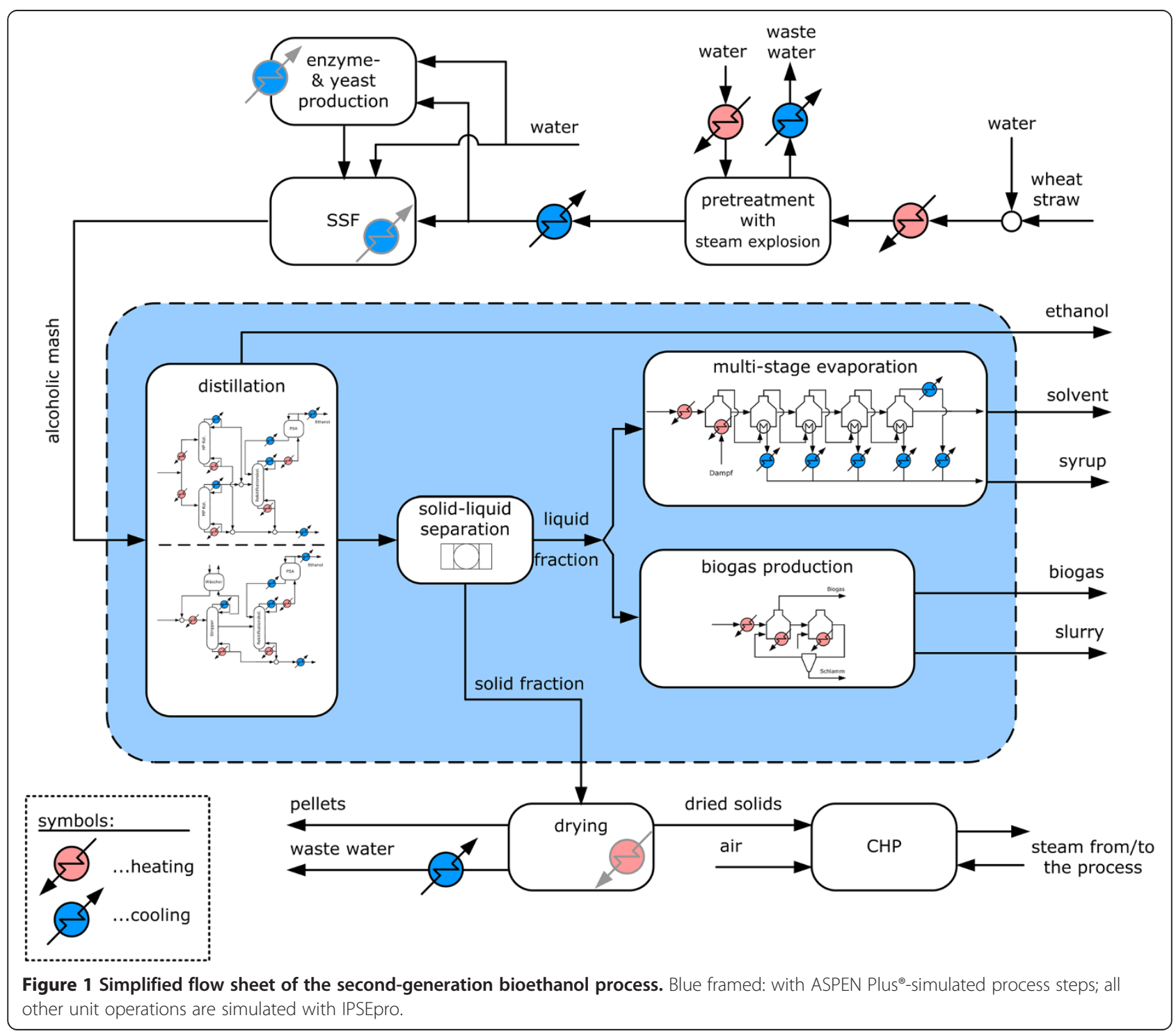


simultaneous saccharification and fermentation (SSF). One drawback in the fermentation of lignocellulosic feedstock is that $\mathrm{C}_{5}$-sugars cannot be fermented by baker's yeast, which is the most common organism in first-generation bioethanol. This fact results in either pentoses like xylose and arabinose remaining unfermented in the slurry or much more expensive yeast has to be utilized.

\section{Downstream process}

In the distillation step, the ethanol is separated from the other components and leaves the head of the column as an azeotropic mixture. This processing step is very energy intensive and requires a smart internal use of the heat. Subsequently the ethanol-water mixture is dehydrated by pressure swing adsorption (PSA) to a desired ethanol content of $99.5 \mathrm{wt} \%$. The residue gained at the bottom of the distillation column is called stillage. This is a suspension comprising water, lignin, and other organic components that are not utilized during the SSF. The stillage is subsequently subjected to solid-liquid separation, where it is split into insoluble solids and a liquid fraction. The solids, mainly containing lignin, are used after a drying step in the co-generation plant for process steam and power generation.

A common method in treating the liquid fraction of the distillation stillage is evaporation. It is used to separate the main constituents of the distillation stillage, water and soluble organic compounds, to make them accessible for reutilization in the process or as by-products [5-7]. From an energetic point of view this stillage treatment step is disadvantageous, since a multistage evaporation utilizes a high amount of primary steam to evaporate water and to produce a concentrate. It is therefore not unreasonable to use the liquid fraction rich in organic matter to produce biogas. With biogas as an additional main product, a more variable process control can be maintained, and the unused sugar from the SSF, proteins, and extracts can be thus exploited in the production of biogas, which results in a cascading use of sugar. The biogas production consists of an anaerobic fermentation, and for wastewater treatment, a subsequent aerobic step could be implemented.

\section{Methods}

In this work the downstream processes for an annual production of 100,000 tons of ethanol from wheat straw were simulated, with a set operation time of 8,000 h/a. The overall production process (background process) was modeled with the equation-oriented flow sheet simulation program IPSEpro [8]. The results for the upstream process from the IPSEpro simulation provide the basis for further simulation done with the modeling tool ASPEN Plus ${ }^{\circ}$. All the data obtained from the simulation is then further used for a pinch analysis of the overall process to be able to compare the different configurations of stillage treatment. In addition, the impact of biogas as a co-product on the process efficiency is determined. The necessary lower heating values (LHV) of biomass are all calculated using the PLS-Model of Friedl [9].

\section{Starting situation}

The specified process stream enters the distillation at atmospheric pressure and at a temperature of $37^{\circ} \mathrm{C}$. The composition, as a result from the IPSEpro simulation, is shown in Table 1. The chosen representative components from the ASPEN Plus ${ }^{\circ}$ simulation database including formula, type, and component are also listed in this table. The remaining fractions of cellulose and hemi-cellulose resulting from upstream processing are represented by the solid components glucan $\left(\mathrm{C}_{6} \mathrm{H}_{10} \mathrm{O}_{5}\right)$ and xylan $\left(\mathrm{C}_{5} \mathrm{H}_{8} \mathrm{O}_{4}\right)$, respectively. It can be also seen that the alcoholic mash entering distillation has an ethanol mass fraction of around $4 \mathrm{wt} \%$ and water is the main component with more than $80 \mathrm{wt} \%$. With the rather low ethanol content in the alcoholic mash compared to the ethanol production based on corn, an additional energy input in the distillation section could be expected.

\section{Distillation}

Two different designs for the distillation of lignocellulosic fermentation broth were chosen, a two-column and a three-column setup. The configurations are based on already existing models from the National Renewable Energy Laboratory [5] and the Technical University of Lund, respectively [7]. Detailed information about the different column specifications is listed in Table 2.

The two-column distillation variant consists of a beer column and a rectification column. Both are operated at an overhead pressure around 2 bar, whereas the number of stages, the related column efficiency, and the reflux ratio differ. The vaporized ethanol-water mixture is removed through a side draw and is then fed into the rectification column without condensation. Due to the fact that both columns are operated at the same pressure level, it is not possible to utilize the condensation heat from one column to heat the other.

However, this is the case in the three-column setup, because the two parallel stripper columns and the rectification column are operated at 3, 1.25, and $0.3 \mathrm{bar}$, respectively. As a result, the second stripper column (at $1.25 \mathrm{bar}$ ) can be heated with the first stripper column condensation heat. This also applies to the rectification column, where condensation heat from the second stripper column is utilized.

In both configurations the azeotropic ethanol-water mixture exiting at the top of the rectification column is 
Table 1 Composition of the process stream fed to the distillation column

\begin{tabular}{|c|c|c|c|c|}
\hline \multirow[t]{2}{*}{ Component } & \multirow{2}{*}{$\begin{array}{l}\text { Mass fraction } \\
\text { (wt\%) }\end{array}$} & \multicolumn{3}{|c|}{ ASPEN Plus ${ }^{\circledast}$ simulation } \\
\hline & & Formula & Type & Component name \\
\hline Water & $80.35 \%$ & $\mathrm{H}_{2} \mathrm{O}$ & Conv & Water \\
\hline Ethanol & $4.007 \%$ & $\mathrm{C}_{2} \mathrm{H}_{6} \mathrm{O}$ & Conv & Ethanol \\
\hline Acetic acid & $0.63 \%$ & $\mathrm{C}_{2} \mathrm{H}_{4} \mathrm{O}_{2}$ & Conv & Acetic-acid \\
\hline Furfural & $0.30 \%$ & $\mathrm{C}_{5} \mathrm{H}_{4} \mathrm{O}_{2}$ & Conv & Furfural \\
\hline Glycerol & $0.085 \%$ & $\mathrm{C}_{3} \mathrm{H}_{8} \mathrm{O}_{3}$ & Conv & Glycerol \\
\hline $\mathrm{CO} 2$ & $0.078 \%$ & $\mathrm{CO}_{2}$ & Conv & Carbon-dioxide \\
\hline Cellulose & $0.575 \%$ & $\mathrm{C}_{6} \mathrm{H}_{10} \mathrm{O}_{5}$ & Solid & Glucan \\
\hline Hemi-cellulose & $0.27 \%$ & $\mathrm{C}_{5} \mathrm{H}_{8} \mathrm{O}_{4}$ & Solid & Xylan \\
\hline Lignin & $4.15 \%$ & $\mathrm{C}_{x} \mathrm{H}_{x} \mathrm{O}_{x}$ & Solid & Lignin \\
\hline C5-monosaccharides & $4.66 \%$ & $\mathrm{C}_{5} \mathrm{H}_{10} \mathrm{O}_{5}$ & Conv & D-xylose \\
\hline C6-monosaccharides & $0.00 \%$ & $\mathrm{C}_{6} \mathrm{H}_{12} \mathrm{O}_{6}$ & Conv & Dextrose \\
\hline Yeast & $0.56 \%$ & $\mathrm{CH}_{x} \mathrm{~N}_{x} \mathrm{O}_{x} \mathrm{~S}_{x}$ & Solid & Biomass \\
\hline Enzymes & $0.18 \%$ & $\mathrm{CH}_{x} \mathrm{O}_{x} \mathrm{~N}_{x}$ & Conv & Zymo \\
\hline Ash & $1.385 \%$ & $\mathrm{SIO}_{2}$ & Solid & Silicon dioxide \\
\hline Extractives & $1.85 \%$ & $\mathrm{C}_{18} \mathrm{H}_{32} \mathrm{O}_{2}$ & Conv & Linoleic acid \\
\hline Plant protein & $0.92 \%$ & $\mathrm{C}_{5} \mathrm{H}_{9} \mathrm{NO}_{4}$ & Conv & L-glutamic acid \\
\hline Sum & $100 \%$ & $\mathrm{H}_{2} \mathrm{O}$ & Conv & Water \\
\hline
\end{tabular}

further dehydrated by PSA to reach the requested ethanol content of $99.4 \mathrm{wt} \%$.

\section{Solid-liquid separation}

Subsequent to both distillation processes, the two-column and the three-column, a Pneumapress pressure filter is used for solid-liquid separation. In the former setup, all

Table 2 Specifications of the two-column and three-column distillation setup in the ASPEN Plus ${ }^{\circledR}$ simulation

\begin{tabular}{lll}
\hline & Two-column & Three-column \\
\hline Beer/stripper column 1 & 2.03 bar & 3 bar \\
Operational pressure & 32 & 25 \\
Number of stages (actual) & $48 \%$ & $50 \% *$ \\
Column efficiency & 3 & 2.3 \\
Reflux ratio & & \\
Beer/stripper column 2 & - & 1.25 bar \\
Operational pressure & - & 25 \\
Number of stages (actual) & - & $50 \% *$ \\
Column efficiency & & 1.4 \\
Reflux ratio & 2.03 bar & \\
Rectification column & 60 & 0.3 bar \\
Operational pressure & $57 \%$ & $75 \% *$ \\
Number of stages (actual) & 3.2 & 2.1 \\
Column efficiency & & \\
Reflux ratio & &
\end{tabular}

*Murphree efficiency. the insoluble solids exit the system at the bottom of the beer column. For the three-column configuration, it is assumed that these solids leave at the bottoms of columns 1 and 2. The design and configuration of the solid-liquid separation is based on the given literature $[5,7]$, and the assumed insoluble solids present in the stillage are listed in Table 1 with the type denotation 'Solid'.

\section{Evaporation}

As mentioned before, one possible stillage treatment method is a multistage evaporation system where the liquid fraction gained from solid-liquid separation is utilized. In this particular case, a five-stage co-current configuration is chosen to regain the water and to generate a syrup with a targeted dry matter (DM) content of $60 \%$. The water can be recirculated into the process and the syrup could be utilized for energy and heat production, as common in the lignocellulosic ethanol process [10].

\section{Biogas production}

The second stillage treatment concept is a further utilization of the biogenic residue due to anaerobic fermentation. With a chemical oxygen demand (COD) of $154 \mathrm{~g} / \mathrm{l}$ in the liquid fraction of the solid-liquid separation, defined reactions, and the respective conversion rates implemented into ASPEN Plus, a resulting COD removal of $72 \%$ and a certain amount of biogas will be obtained. 


\section{Background process}

The background process consists of the upstream unit operations as preheating, steam pretreatment of the straw, condensation and cooling of steam at different pressure levels, the enzyme production, and SSF, as well as of the drying section followed by a combined heat and power plant (CHP) in the downstream process. The data taken into account for the background process is based on a previous simulation work [11]. As a pretreatment method in the upstream process section, steam explosion is chosen and the conversion to ethanol is performed by SSF with the conversion of only $\mathrm{C}_{6}$-sugars to ethanol. Furthermore, it is assumed that the enzyme production is done on-site. From a material balance point of view, more than 648,000 tons of fresh straw (with 90\% DM) are annually fed into the process to generate 100,000 tons per year. Detailed information about the upstream process can be found in Kravanja [11].

\section{Pinch analysis}

Information about the systems potential for heat integration is provided by the application of pinch analysis. Thereto all process streams are separated either in cold or hot streams and plotted in a temperature-enthalpy diagram according to Linnhoff March [12]. The required mass flows and specific heat capacities are taken from the simulations in order to determine a closed mass and heat balance. The pinch analysis is done with a program based on Mathematica (V7.01.0) which has been successfully applied in a previous study of the lignocellulosic ethanol production process [13]. The program generates a plot of the grand composite curve (GCC), as well as a plot of the hot composite curve ( $\mathrm{HCC}$ ) and cold composite curve (CCC). The maximum heat integration and minimum hot and cold utility demand can then be read off from these plots. As shown in Figure 2, information about the heating requirements, the cooling requirements, and the integrated heat for the different process configurations is provided.

\section{Results and discussion}

The efficiency of the overall process is calculated from the ratio of the product energy content to the energy content of the raw material - all based on the $\mathrm{LHV}_{\mathrm{dry}}$. With an annual straw demand of almost 650,000 tons (406 MW) and considering just ethanol as a product, the process efficiency reaches $23 \%$. It is assumed that the energy demand of the overall process can be covered due to the utilization of the solids from solid-liquid separation in a CHP, which was proven for all cases by the process simulation. Burning the solids for steam and power production is a common practice in ethanol production and the most beneficial option [14].

In the ethanol production from whole grain or cane molasses, the liquid fraction of the distillation stillage is also sent to a multistage evaporation system to recover the water. The concentrated syrup gained from evaporation is then further utilized in the dried distiller grains and solubles (DDGS) production or as a low-value feed additive, respectively [15]. Generating by-products like that results in a positive effect on the overall energy efficiency of the process. The simulation of the multistage evaporation for the lignocellulosic feedstock to ethanol process shows that almost 300,000 tons per year of syrup (60\% DM) with a $\mathrm{LHV}_{\text {dry }}$ of $108 \mathrm{MW}$ are produced. This syrup can be seen as an accountable by-product when utilized in the CHP.

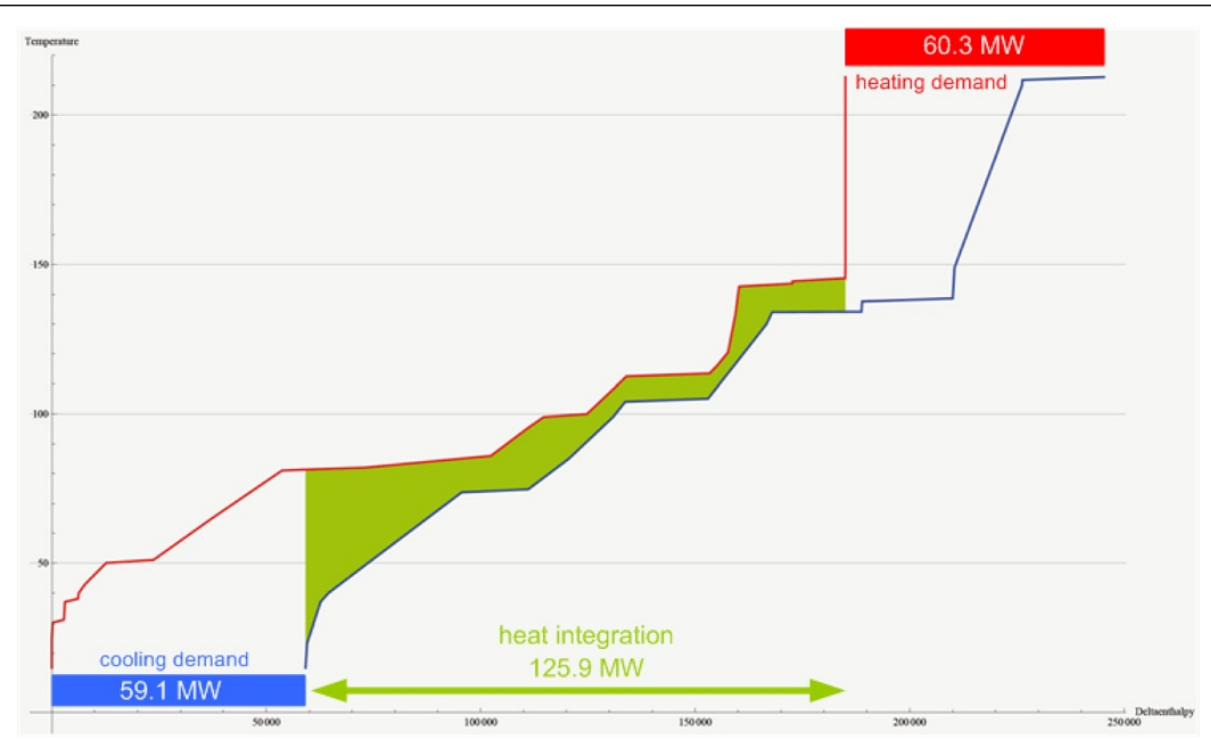

Figure 2 Composite curves. HCC (red) and CCC (blue) of the three-column distillation system with a five-stage evaporation system for stillage treatment (process configuration B). 
Furthermore, 1.25 million tons of water (solvent) is accessible for reutilization in the process. But, as Wilkie et al. [15] state, the buildup of inhibitors in the solvent prevents a $100 \%$ water recycling. Taking the energy content of the syrup into account, whether directly or via the energetic conversion into excess electricity, the process efficiency is more than doubled (49\%).

With biogas production as the chosen stillage treatment, the simulation shows that annually 195,276 tons of biogas with a methane content of $50 \mathrm{vol} \%$ can be produced. This accounts for 95.7 MW additionally to the 93.8 MW energy content in the $100.000 \mathrm{t} / \mathrm{a}$ of bioethanol produced. Based on the set specifications for anaerobic digestion, a reactor size greater than $63,000 \mathrm{~m}^{3}$ with a HRT of more than 10 days would be necessary. The residue from biogas production contains a high fraction of water and has therefore to be further treated. Thereby, annually 76.427 tons of mud with a dry matter content of 75\% DM incurs. As a result, 1.7 million tons of water per year is accessible for recirculation in the process. With a nonthermal utilization of the eutrophic mud, certain fractions of nitrogen, phosphor, and minerals could be recycled into the agriculture [16].

In both stillage treatment methods, reducing the energy demand goes along a decrease in water demand. A reduction of the heat and energy requirements in the downstream section will have a positive effect on the overall process efficiency, because more excess electricity will be available. Thereto the different designs of distillation and stillage treatment are analyzed relating to heat demand, cooling demand, and heat integration. Furthermore, the minimum energy consumption per kilogram of ethanol produced is calculated, by taking also the background process into account. Table 3 shows the obtained results from pinch analysis as well as the calculated minimum energy consumption. The latter is the quotient of the required heat demand for the overall process and the amount of ethanol produced. The evaluation of the four different concepts, which are listed in Table 3, shows that configurations $B$ and $D$ are preferable for the respective stillage treatment by evaporation and biogas production. Configuration B reduces the energy consumption by $1.2 \mathrm{MJ} / \mathrm{kg}$ of ethanol to a total of $17.2 \mathrm{MJ} / \mathrm{kg}_{\mathrm{EtOH}}$. As shown by the composite curves in Figure 2, by applying a five-stage evaporation system for stillage treatment, the three-column distillation concept requires 60.3 MW for heating and 59.1 MW for cooling. This accounts for savings of 3.7 MW in hot utility and 5.7 MW in cold utility compared to the downstream process including a two-column distillation concept.

Replacing the evaporation system with an anaerobic digester reduces the energy consumption by more than one third to $10 \mathrm{MJ} / \mathrm{kg}_{\mathrm{EtOH}}$, with regard to the threecolumn distillation setup. The pinch analysis also shows that this configuration requires the respective heating and cooling utility of 35.2 and $32.7 \mathrm{MW}$.

\section{Conclusions}

Due to the fact that the distillation is a standard technology used for continuous separation of ethanol from mixtures, the optimization of this process section is of high importance. A reduction of the energy requirements in this process section will benefit the overall process efficiency. Data obtained from the downstream process simulation shows that the distillation section accounts for $60 \%$ of the overall energy demand. This share can be reduced by an implementation of the correct distillation setup accompanied with the respective stillage treatment. The demanded energy to run the process can be covered by the utilization of the dried solid residues from solid-liquid separation, which makes it selfsufficient. Not only the self-sufficiency reduces solid waste disposal costs, but also excess electricity could generate additional revenue. Hence, a reduction of energy demand in the downstream process is desirable. The resulting savings not only lead to an improvement of the overall process efficiency, they also allocate byproducts as heat, electricity, and pellets. For the concepts containing biogas production, the overall heat demand could also be covered by the biogas, as it is required. Another option would be the upgrading of

Table 3 Comparison of heating demand, cooling demand, and integrated heat for the different process configurations

\begin{tabular}{|c|c|c|c|c|c|}
\hline & \multirow[t]{2}{*}{ Unit } & \multicolumn{2}{|c|}{ Five-stage evaporation } & \multicolumn{2}{|c|}{ Biogas production } \\
\hline & & $\begin{array}{l}\text { Two-column } \\
\text { distillation }\end{array}$ & $\begin{array}{l}\text { Three-column } \\
\text { distillation }\end{array}$ & $\begin{array}{l}\text { Two-column } \\
\text { distillation }\end{array}$ & $\begin{array}{l}\text { Three-column } \\
\text { distillation }\end{array}$ \\
\hline Heating demand & MW & 64.0 & 60.3 & 38.3 & 35.2 \\
\hline Cooling demand & MW & 64.8 & 59.1 & 39.9 & 33.7 \\
\hline Heat integration & $\mathrm{MW}$ & 91.9 & 125.9 & 69.5 & 103.4 \\
\hline Pinch point & ${ }^{\circ} \mathrm{C}$ & 116.4 & 116.6 & 116.4 & 142.9 \\
\hline Minimum energy consumption per kilogram of ethanol & $\mathrm{MJ} / \mathrm{kg}_{\mathrm{EtOH}}$ & 18.4 & 17.2 & 11.1 & 10 \\
\hline Process configuration & & A & B & C & D \\
\hline
\end{tabular}


biogas to utilize it as an additional by-product. A combined production of bioethanol and biogas leads to a reduction of GHG emissions and maintains a sustainable pathway to the independency on fossil fuels.

This work shows that the three-column distillation configuration is favorable in both stillage treatment concepts, but it is still questionable if the moderate savings in heating and cooling demand justify the additional expenses in equipment. Therefore, a technoeconomic evaluation of the process variants should be applied in future work.

\section{Abbreviations \\ CCC: cold composite curve; CHP: combined heat and power plant; COD: chemical oxygen demand; DM: dry matter; GCC: grand composite curve; HCC: hot composite curve; LCA: life cycle analysis; LHV dry: lower heating value; PSA: pressure swing adsorption; SSF: simultaneously saccharification and fermentation.}

\section{Competing interests}

The authors declare that they have no competing interests.

\section{Authors' contributions}

$\mathrm{TL}$ carried out the simulations in ASPEN Plus ${ }^{\oplus}$, performed the pinch analysis, and drafted the manuscript. PK carried out the simulations in IPSEpro. AF conceived of the study, participated in its coordination, and helped to draft the manuscript. All authors read and approved the final manuscript.

Received: 30 October 2014 Accepted: 6 November 2014

Published online: 24 December 2014

\section{References}

1. Winter R (2011) Biofuels in the transport sector 2011 - summary of the data for the Republic of Austria, Federal Ministry for Agriculture, Forestry, the Environment and Water Management

2. Jacques KA, Lyons TP, Kelsall DR (2003) The alcohol textbook, 4th edn. Nottingham University Press, Nottingham, UK

3. Hahn-Hägerdal B, Galbe M, Gorwa-Grauslund MF, Lidén G, Zacchi G (2006) Bio-ethanol - the fuel of tomorrow from the residues of today. Trends Biotechnol 24:549-556

4. Kaltschmitt M, Hartmann H, Hofbauer H (2009) Energie aus Biomasse. Springer-Verlag, Berlin Heidelberg

5. Aden A, Ruth M, Ibsen K, Jechura J, Neeves K, Sheehan J, Wallace B (2002) Lignocellulosic biomass to ethanol process design and economics utilizing co-current dilute acid prehydrolysis and enzymatic hydrolysis for corn stover, National Renewable Energy Laboratory (NREL)., s.l.: Storming Media. NREL/TP-510-32438

6. Wingren A, Galbe M, Zacchi G (2008) Energy considerations for a SSF-based softwood ethanol plant. Bioresour Technol 99(7):2121-2131

7. Sassner P (2007) Lignocellulosic ethanol production based on steam pretreatment and SSF. Lund University

8. Kravanja P, Friedl A (2011) Process simulation of ethanol from straw validation of scenarios for Austria. Chem Eng Trans 25:863-868

9. Friedl A (2005) Prediction of heating values of biomass fuel from elemental composition. Anal Chim Acta 544:191-198

10. Wallace R, Ibsen K, McAloon A, Yee W (2005) Feasibility study for co-locating and integrating ethanol production plants from corn starch and lignocellulosic feedstocks., NREL/TP-510-37092, Revised January Edition: USDA/USDOE/NREL

11. Kravanja P, Könighofer K, Canella L, Jungmeier G, Friedl A (2011) Perspectives for the production of bioethanol from wood and straw in Austria: technical, economic, and ecological aspects. Clean Techn Environ Policy 14(3):411-425

12. Linnhoff March Ltd (1998) Introduction to pinch technology. Linnhoff March Ltd. Now part of KBC Advanced Technologies plc, Northwich, UK

13. Modarresi A, Kravanja P, Friedl A (2012) Pinch and energy analysis of lignocellulosic ethanol, biomethane, heat and power production from straw. Appl Therm Eng 43:20-28
14. Chovau S, Degrauwe D, Van der Bruggen B (2013) Critical analysis of techno-economic estimates for the production cost of lignocellulosic bio-ethanol. Renew Sust Energ Rev 26:307-321, doi: 10.1016/j.rser.2013.05.064

15. Wilkie AC, Riedesel KJ, Owens JM (2000) Stillage characterization and anaerobic treatment of ethanol stillage from conventional and cellulosic feedstocks. Biomass Bioenergy 19:63-102

16. Lassmann T, Kravanja P, Friedl A (2011) Prozesssimulation der Produktion von Ethanol und Methan aus lignocellulosehaltigen Rohstoffen. Chemie Ingenieur Technik 83(10):1609-1617

\section{Submit your manuscript to a SpringerOpen ${ }^{\odot}$ journal and benefit from:}

- Convenient online submission

- Rigorous peer review

- Immediate publication on acceptance

- Open access: articles freely available online

- High visibility within the field

- Retaining the copyright to your article

Submit your next manuscript at springeropen.com 